\title{
A grounded theory approach to assess indoor soundscape in historic religious spaces of Anatolian culture: A case study on Hacı Bayram Mosque
}

2018, Vol. 25(2) 137-150

(C) The Author(s) 2018

Reprints and permissions: sagepub.co.uk/journalsPermissions.nav DOI: 10.1177/1351010X18763915 journals.sagepub.com/home/bua

\section{Semiha Yilmazer and Volkan Acun}

\begin{abstract}
This study presents a research that is concerned with the indoor soundscape in historical mosque. Hacl Bayram Mosque and its surroundings area of Hamamönü has been selected as the research site due to being the historical centre of Ankara. Although there are studies concerned with the acoustical characteristics of mosques, there is not enough research focusing on user's expectation and interpretation of the indoor soundscape within a historical space. This study adopts the user-focused grounded theory to capture individuals' auditory sensation and interpretation of the indoor soundscape within a historical mosque. In-depth interviews are held with congregation of the mosque and with the individuals sitting around the surrounding area. Based on their subjective responses, a theoretical framework is generated to gain an insight on the factors that affect individuals understanding and expectation from mosques. The conceptual framework generated through grounded theory shows how indoor soundscape may influence their individuals' response to the physical environment of the mosque showing the association between the soundscape elements, spatial function and place identity.
\end{abstract}

\section{Keywords}

Indoor soundscape, grounded theory, historical religious space, mosque, auditory sensation

\section{Introduction}

Haci Bayram Mosque is built on the historic city centre of Ankara, over five centuries ago. It is among the oldest mosques of Ankara and surrounded by historic buildings, which predate it over more than a millennium. The site where the mosque is built on is used by many civilisations for religious purposes. Over the decades, the mosque and its surrounding area have undergone

Department of Interior Architecture and Environmental Design, Faculty of Art, Design and Architecture, Bilkent University, Ankara, Turkey

\section{Corresponding author:}

Semiha Yilmazer, Department of Interior Architecture and Environmental Design, Faculty of Art, Design and Architecture, Bilkent University, 06800 Ankara, Turkey.

Email: semiha@bilkent.edu.tr 
numerous restoration and reconstruction efforts. However, its spatial characteristic as a historic religious space has stayed the same. Spatial characteristic of spaces such as this reflects its religious philosophy and symbolism, but they are not limited to these. ${ }^{1,2}$ They are also associated with historic background of communities such as culture and social structure.

From churches to mosques, acoustic comfort is considered as a significant factor in historic religious spaces. During the Ottoman era, Sinan the architect placed ceramic pots within the domes to increase the sound absorption of the dome and to control the acoustical comfort of the congregation. ${ }^{3-5}$ There are various researches concerned with the acoustical properties of both historic ${ }^{3-8}$ and contemporary mosques. ${ }^{6,9,10}$ However, there is a lack of research on individuals' subjective perception of the religious places. Objective measurements of acoustical properties of religious spaces may not provide sufficient information about individuals' perception and interpretation of auditory sensation. In order to acquire an in-depth knowledge, we should explore individuals' feelings and how they perceive their auditory environment through the soundscape approach.

The difference between the soundscape and the traditional energy transfer approach comes from the fact that soundscape is concerned with individuals' communication with the environment through sound, whereas the latter is concerned with the transfer of energy. ${ }^{11}$ According to ISO 12913-1, soundscape is defined as 'the acoustic environment perceived or experienced and/or understood by a person or people, in context'. ${ }^{12}$ ISO 12913-1 also proposed a framework that consists of seven items. This framework includes sound sources; acoustic environment; auditory sensation; and interpretation of the auditory sensation, responses and outcomes and puts emphasis on the context of sound as a major item. Soundscape approach gained popularity during the last decade, but it still lacks a standardisation. Numerous researches have been conducted to evaluate soundscapes. Soundwalk approach is perhaps one of the most common methods that has been implemented by the researchers. ${ }^{13-19}$ However, this method may not be applied to indoor spaces, especially to a mosque. Soundwalks can potentially be used in large indoor spaces, such as large shopping malls or airports. In large, touristic mosques (e.g. Ayasofya Mosque and Sultan Ahmet Mosque), there are zones dedicated to tourist where visitors can walk around without interrupting the congregation, but this is not the case with the Hac1 Bayram Mosque as the interior space of the mosque is simply not large enough. Semantic differential scales, focus groups, interviews and questionnaire survey are commonly adopted tools to capture the subjective response of participants. ${ }^{15,20-22}$

Depending on the function, indoor soundscapes can have a complex sound environment. In order to discover the subjective sound experience of an indoor space, this study will use the qualitative approach of grounded theory (GT). Historic Haci Bayram Mosque is used as the research setting for this method. Through the implementation of GT, this article aims to explore individuals' interpretation of the sound environment of this historic mosque and its surrounding area and their auditory sensation, with a user-focused approach.

\section{GT}

GT is widely used qualitative research method to systematically analyse qualitative data. This method can be briefly defined as 'Discovering theory from data' ${ }^{23}$ Data collection and analysis are interrelated, meaning the data analysis starts as soon as data are gathered. The main tools of gathering data are interviews, observations and memos. GT is based on two core principles, constant comparison and theoretical saturation. Constant comparison process starts as soon as the data are obtained. Newly obtained data are compared with the previous ones, and through coding, they are broken down into pieces, categorised and connected with each other to construct an inductive theory. ${ }^{20,23,24}$ Through the constant comparison process, the researcher moves back and forth between the code and the emerging data for similarities and differences. Theoretical saturation 
ensures the representability and consistency of the data. ${ }^{24}$ In order to achieve this, participants should be chosen from those who will provide minimum difference and those who will provide maximum. In this way, samples will more likely contribute to theory building which enables fully developed categories and saturated data. ${ }^{20,25}$ With regard to this, the quality and depth of the information provided by the data is more important than the number of interviews. Once the data are saturated, the data collection stops. ${ }^{23,24}$

Due to its systematic, traceable, user-focused approach and its ability to provide in-depth knowledge about the phenomenon, GT is used by number of researchers for soundscape research. ${ }^{20}$ GT method is introduced to the field of soundscape by Fiebig et al. ${ }^{26}$ and Schulte-Fortkamp and Fiebig. ${ }^{27}$ They created a framework which points out that the individuals evaluate soundscapes based on the social and cultural structures they are imbedded in. Liu and $\mathrm{Kang}^{28}$ carried out an extensive GT research in Sheffield. According to their findings, individuals place value on sound events based on the positive and negative behaviours associated with it. GT method is also used to examine indoor soundscapes. Mackrill et al. ${ }^{29}$ used GT for conceptualising the lived-in soundscape experience of a hospital ward. They find that patients can cope with the soundscape by accepting and habituating to the soundscape. Çankaya and Yilmazer ${ }^{30}$ carried out a GT research in different types of high school classrooms and found out that sounds that do not belong to the sound environment are perceived negatively. Finally, Acun and Yilmazer ${ }^{20}$ investigated the soundscape of openoffice environments. Researchers developed a framework which indicated that soundscape interpretation depends on the context of the sound and given information about coping methods.

A limitation of the GT survey comes from the fact that the whole process is managed by the researcher. Generalisability of the theory can be limited due to the researcher's lack of experience, style and quality of the interviews..$^{20,24,31-33}$ During the data collection and analysis, the researcher is not value neutral. Researcher should put emphasis on staying objective as much as possible to minimise any negative effect. Additionally, since it is the first time, indoor soundscape in historic religious spaces of Anatolian culture has been picked up as a context that we can call it 'unique context', and it might create some curiosity on the method, GT approach, which we are aiming to introduce to the literature. As a researcher, we believe that our mission is also to put valuable contributions on the different case studies, which are different selected building environments.

\section{Method}

\section{Case study setting}

The main reason for choosing this mosque is because of its historic and cultural background. Hac1 Bayram Mosque is located at the historic centre of the city. Its visitors are not limited to those living in the region. People from all around the city come to this site for its religious and sociocultural function. Alongside with being a religious hub, for centuries, it has been used for recreation, relaxation and coming together with others.

Hacı Bayram Mosque is located on a hill at the historic Ulus district of Ankara. Religious history of the location dates back more than 2000 years. During the ancient times, this site was used to worship the Anatolian deities, Cybele and Men. After Roman conquest, Temple of Augustus (Monumentum Ancyranum) was built on its place. Temple was converted into a church during the Byzantine rule, and with the Turkish conquest, it was used as a madrassah. ${ }^{34} \mathrm{Hac1}$ Bayram Mosque was constructed right adjacent to the temple at 1427. Mosque has the characteristics of early Ottoman era architecture. South-eastern corner of the mosque touches the western wall of the temple with approximately $40^{\circ}$ of angle (Figure 1). Mausoleum of Haci Bayram-I Veli is attached to the southern wall of the mosque. Mausoleum is a domed structured that is constructed shortly after 


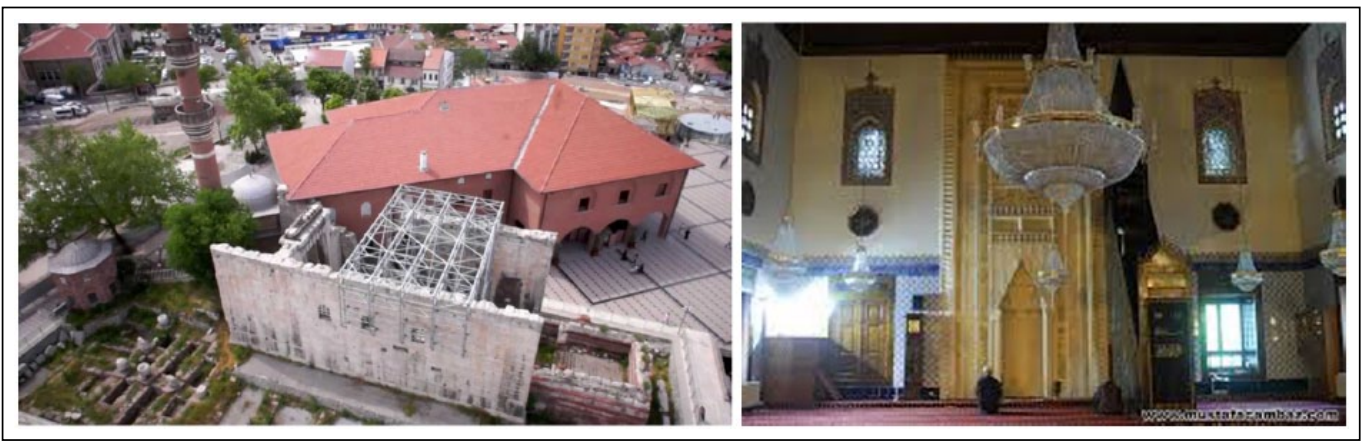

Figure I. Hacı Bayram Mosque and the Temple of Augustus (left) and interior view of the mosque (right).

the mosque, with the death of Haci Bayram (Figure 1). The minaret of the mosque is attached to the south-eastern corner of the mausoleum. Even though both of these structures are attached to the mosque, they are independent structures which cannot be accessed from inside the mosque. Over the centuries, the mosque has undergone many restorations, and some parts were added to the original mass during these restorations. ${ }^{34,35}$

The mosque was the central part of an Islamic social complex (Külliye) with buildings spread around the site asymmetrically, most of which are non-existent today. The main mass of the mosque that survived until today has a rectangular stone foundation, brick walls with wooden girders, wooden cassette ceiling and a hipped roof. Mosque has two storeys. On the first floor, the main prayer hall is located after narthex (Figure 2). This hall is two-storey high and oriented towards the plaster mihrap. The upper floor has a cantilevered slab, facing the mihrap. First floor has rectangular windows, while the second floor has pointed arch windows. In the main prayer hall, inner surface of the walls are covered with glazed tiles up to the top of the first row of windows. Upper portion of the walls are painted plainly. After the renovation efforts of 2011, the floor area of the mosque has increased to total of $2500 \mathrm{~m}^{2} .{ }^{35}$

Equivalent continuous A-weighted sound levels (LAeq) were measured during the interviews, using the Bruel \& Kjaer sound level meter type 2230. In situ measurements of LAeq are performed outside the mosque, during the interviews, in order to understand the acoustical conditions of the area surrounding the mosque. These measurements are carried out for 3 days with Bruel \& Kjaer sound level meter type 2230, over 15 -min intervals, at a height of $150 \mathrm{~cm}$. The mean LAeq rating of these measurement is $58.2 \mathrm{~dB}(\mathrm{~A})$. A three-dimensional (3D) model of the mosque is prepared with SketchUp 2015 for computer simulation. SketchUp model is exported to ODEON Room Acoustics Software version 12 basic edition to simulate the reverberation time (T30) estimations. ODEON results indicate that the T30 values are ranging from 1.2 to 1.5 for the common speech frequencies of 500-2000 Hz. The average Speech Transmission Index (STI) value of the mosque is 0.56, which corresponds to fair amount of speech intelligibility. During the survey, participants stated that they can clearly understand imam's speech most of the time. It should be noted that this article does not aim to make any interference between the acoustical parameters of the mosque and the soundscape. In situ measurements of LAeq and the ODEON simulation are only held to gather descriptive information about the acoustical parameters of the mosque.

\section{Participants}

Purposive sampling is used to choose the participants. Due to religious concerns, it was not possible to held interviews in the mosque. Therefore, the interviews were held in the historic square 


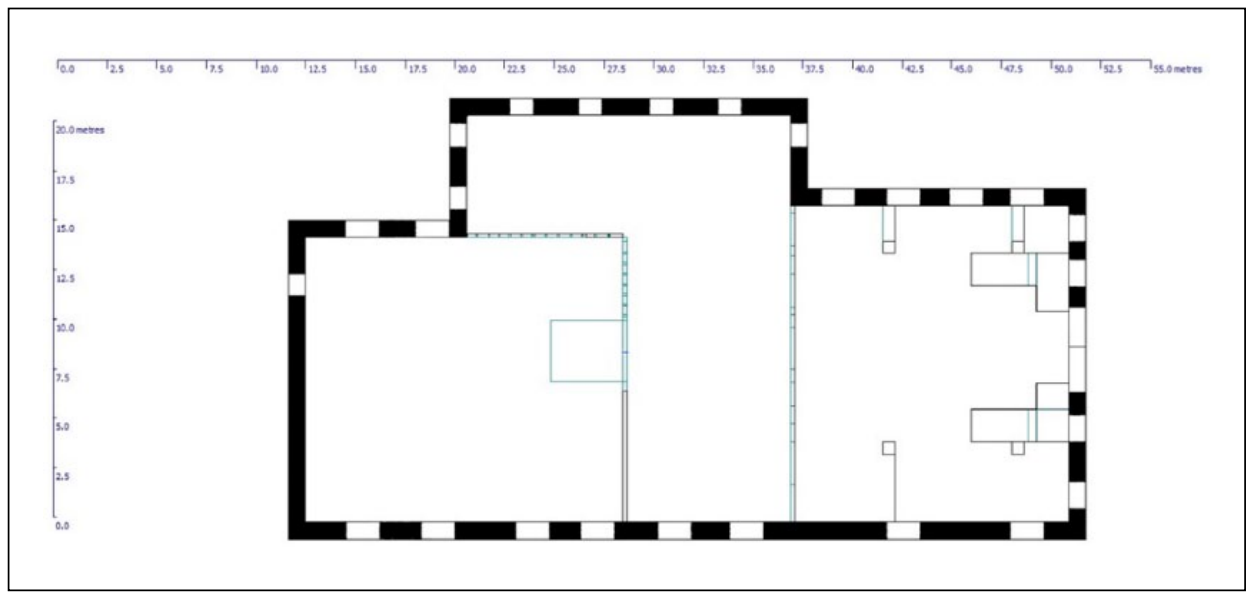

Figure 2. Plan of the mosque.

that surrounds the mosque. In order to ensure that the participants are familiar with the indoor space of the mosque, the participants were chosen among those who were leaving the mosque after a prayer/sermon. This ensures that the participant has spent at least 10-20 min inside the mosque. Along with this, before initiating any interview, we have asked whether the participant has been in the mosque that day and how frequently they visit the mosque.

Sample group consists of 15 males. Prayer sessions are dominated by male population. Because of this, it is very hard to find any female who leaves the mosque after a prayer. The very small amount of females whom we found did not prefer to participate in the survey. Age of the sample group varies between 36 and 60 years.

A total of three different days are chosen to conduct the semi-structured interviews. Tuesday is chosen as a workday, in which the participants are mostly those living or working in the area. Friday is considered as a holy day in the Muslim world. Due to this, Friday afternoon prayers are more crowded than any other prayer period. Being the weekend, Saturday has a more diverse community than weekdays as increased number of tourists and those living in further districts of Ankara visit the mosque.

\section{Data analysis}

The major goal of this research is to conduct a qualitative research that reflects users' experience with the soundscape. Therefore, semi-structured interviews are used as the main tool for collecting the GT data. Before beginning the semi-structured interviews, the main questions are formulated to initiate the interviews. These main questions are exploratory, and they are to facilitate the interviews rather than a strict list. The main aim of the interviews is to explore anything that is associated with participants' perception of the sound sources, their sound expectation and preference for a religious/historic site and their satisfaction. Therefore, the questions are open ended and nondirective. During the interviews, significant events and reoccurring themes expressed by the participants are identified and added as new questions. All the interviews are recorded and later transcribed. Once the data reached the theoretical saturation, the interviews were stopped.

Before initiating the data analysis, field recordings are transcribed verbatim. Constant comparison method is used to analyse the interview transcriptions (Figure 3). This method involves several 


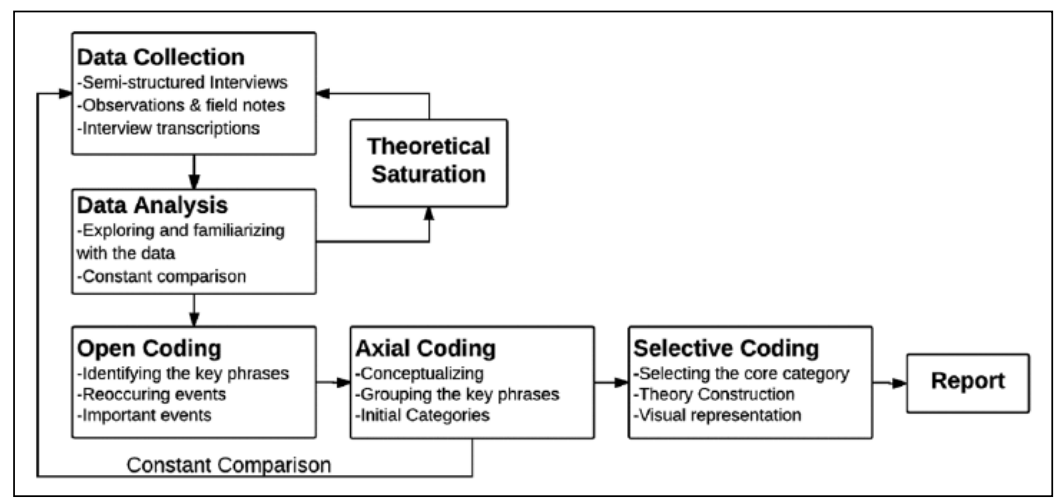

Figure 3. Data analysis process for grounded theory. ${ }^{20}$

phases of coding procedures. Constant comparison starts with open coding. This process separated the transcriptions, along with the field memos, into key phrases. At this stage, the raw data are read and re-read, in order to get familiar with the data. Each sentence of the interview transcriptions are searched for repetitions, patterns and what is important about these similarities. By identifying each significant event, reoccurring patterns, the data are broken down into pieces, while eliminating the irregular ones. ${ }^{20}$ For example, interviewees' comments regarding their impressions of the mosque are labelled into key phrases as tranquil, peaceful, impressive and so on.

At the second stage, the axial coding, relations between the key phrases generated through the open coding are evaluated, and related phrases are grouped together which created the categories. Categories are titled to reflect its content. As new materials are added under the categories, they were checked whether they fit in with the content and whether the title still reflects the category. The key phrase examples we have previously given (tranquil, peaceful, impressive, etc.) are grouped together which created the category titled 'place identity'. Throughout the analysis, this example is applied to interviewees' each sentence, and all relevant statements are broken down and labelled into key phrases. Table 1 shows an example of the coding process. This grouping of the data created the categories and their subcategories. Last phase of the coding process is the selective coding. In this phase, the main category is selected. Its relation with other categories is investigated and expressed through charts and diagrams.

\section{Results}

A total of six categories are generated in the end of the data analysis. These categories generated after the GT research are spatial function, sound preference, soundscape expectation, interpretation of soundscape, place identity and outcomes (Table 2). Categories are arranged in a framework to visually represent the factors that influence individuals' interpretation of the soundscape, its outcomes and individuals' response (Figure 4). Based on this framework, function of the space is the first major determinant that influences the interpretation of soundscape. Spatial function causes major effect on individuals' soundscape expectation and sound preference.

In a regular public square or in a large indoor space like a shopping mall, hearing prayer would be found bizarre. Great majority of the population neither expect nor prefer to hear that. As seen in Table 1, even a religious person might not prefer this situation because it does not fit in with the spatial function of the space. It would be regarded as out of context. Based on this judgement process, individuals unconsciously interpret the soundscape. Their interpretation leads to certain 
Table I. An example of coding process.

\begin{tabular}{|c|c|c|c|}
\hline Statement & Key phrases & Conceptualisation & Conceptualisation \\
\hline $\begin{array}{l}\text { I don't think the prayer } \\
\text { broadcast in the outdoor } \\
\text { area is appropriate because it } \\
\text { is a public place not everyone } \\
\text { is in proper condition }\end{array}$ & $\begin{array}{l}\text { Spatial function/ } \\
\text { religious function; } \\
\text { sound preference }\end{array}$ & $\begin{array}{l}\text { Prayer broadcasted in } \\
\text { public space is negative } \\
\text { due to religious values }\end{array}$ & $\begin{array}{l}\text { Sound preference due to } \\
\text { spatial function/religious } \\
\text { function }\end{array}$ \\
\hline
\end{tabular}

Table 2. Categories and subcategories generated at the end of data analysis. ${ }^{36}$

\begin{tabular}{|c|c|c|c|c|c|}
\hline \multicolumn{6}{|c|}{ Categories and subcategories } \\
\hline Spatial function & $\begin{array}{l}\text { Soundscape } \\
\text { expectation }\end{array}$ & $\begin{array}{l}\text { Sound } \\
\text { preference }\end{array}$ & $\begin{array}{l}\text { Interpretation } \\
\text { of soundscape }\end{array}$ & Place identity & Outcomes \\
\hline $\begin{array}{l}\text { I. Social function } \\
\text { 2. Religious } \\
\text { function }\end{array}$ & & & & $\begin{array}{l}\text { I. Mystique } \\
\text { 2. Spiritual } \\
\text { 3. Tranquil } \\
\text { 4. Peaceful } \\
\text { 5. Impressive }\end{array}$ & I. Preference \\
\hline
\end{tabular}

feelings which not only enhance the perception of soundscape but also the place identity. Each of these categories and their relations will be explained to demonstrate this process in detail (Figure 4).

\section{Spatial function}

Throughout the research, spatial function of the space is a commonly reoccurring category that is stated by all participants. It creates the foundation of individuals' expectation and preference. Similar to other religious buildings, case study site has two main spatial functions, ${ }^{37}$ the religious function and the social function. Individuals base their expectation and preference in accordance with the spatial function of the space. Based on the participants' responses, religious functions of the mosque are daily prayers, Friday prayers, funerals and visiting the mausoleum of Haci Bayram. The majority of the respondents stated that the most important reason for visiting this most is the mausoleum. The ruins of the Temple of Augustus are also mentioned during the interview, but with one exception, responses are rather indifferent with the presence of the ancient temple. One of the respondents clarified this by stating,

Another important reason why I like this place is the mausoleum. I like to visit all mausoleums, not only this one. The ruins of Temple of Augustus is nice too and it should be respected also but it is the mausoleum I'm interested in.

Besides its religious function, mosque is also a social place. Various different kinds of people come together either in or around the mosque. Some of the social function of the mosque is tied to its religious function. Our observations point out that those who came to the mosque for religious functions (prayer, visiting the mausoleum, etc.) often prefer to stick around the mosque for a time. People do not hesitate to sit near complete strangers and engage in group conversation. A participant explained this situation as 


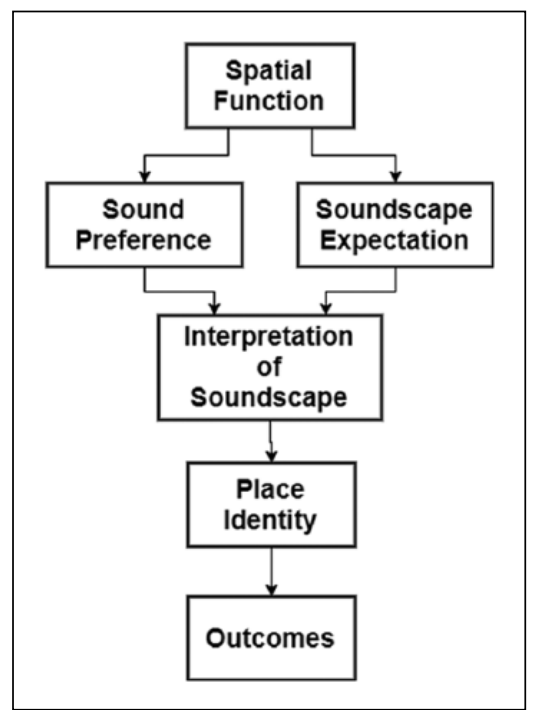

Figure 4. Conceptual framework which shows the association between the categories. ${ }^{36}$

Sometimes it can get very crowded which is nice because while sitting around you can meet new people and start casually chatting.

As the mosque and its surroundings is a historic location, there are tourists and those who visit for cultural values; thus, it can be said that the population around the mosque does not only consist of people with religious purposes.

\section{Soundscape expectation and sound preference}

In order to avoid any confusion between expectation and preference, both notions are explained to the participants, and their opinions are asked in separate questions. There is a strong relation between the spatial function of the space and the soundscape expectation. When it comes to mosques, it is very reasonable to expect spirituality. However, as Hacı Bayram Mosque and its surrounding area has centuries of history, individuals expect something more than they would expect from a regular mosque. The best way to express this is by looking in to participants' statements. A group of participants who visited the mosque for the first time stated that they were disappointed with the overall atmosphere of the mosque. Further inquiry revealed that part of it was caused by the soundscape. When they were inside the mosque, the composition of visual and aural environment evoked a mystique, tranquil and spiritual atmosphere. However, on exiting the mosque, the mystique atmosphere is transformed into a mix of street merchants, shops and traffic. They were expecting the sound environment to be unique like the building itself, but due to blend of out-of-context sounds, they were let down. It is described by one of the participants as 'Just like a regular street'.

Interviews also showed that spatial function has a heavy influence on the individuals' sound preference. When respondents were asked what they would prefer to hear in this place, one of them responded by saying,

I do not prefer to hear anything because in order for a place to have spiritual feeling it should be quiet, religious places should be quiet. 
Overall, individuals place a great importance on the spatial function of the space which determines their soundscape expectation and sound preference. Another respondent said that he finds nothing special about the soundscape because he expects and prefers it to have some degree of variation, but as this is not the case, he feels nothing special about the soundscape. When going to a particular space, participants have a clear idea about what that space is and why they are going to that place. They know what to expect from it and have a predetermined preference. Once they start to hear the soundscape, they subconsciously compare it with the soundscape they expect and prefer. This influences the way they interpret the soundscape. For the quotation above, participant prefers religious spaces to be quiet, and if it is actually a quiet environment, it can be interpreted as a tranquil place.

\section{Interpretation of soundscape}

One of the few sound sources mentioned by the respondents is the music/prayer that is broadcasted both indoor and outdoor areas of the mosque. The majority of the respondents are in favour of this broadcast. However, when it comes to the context of the broadcast, respondents are not in an agreement. Participants did not express any negative statements of the Quran reciting inside the building. After all, it is very usual for a mosque, and it meets their expectation. But when Quran reciting or imam's sermon is broadcasted to outdoors, some respondents feel uncomfortable. According to them, even hearing the Quran is sacred, and it requires the individuals to be in a proper mental and hygienic conditions. Others state that it might not be preferred by everyone. As the mosque is located in a commercial and historic district, it hosts a diverse community. Some of the people are mere tourists without any religious purposes or some of them work/live in the area. Broadcasting prayer to this area is seen by some respondents as a religious pressure. This issue is once again related with the context of the sound. When a sermon or Quran reciting is broadcasted to public area, these individuals perceive that sound negatively even though they are not against any religious values. However, each individual who talked about the broadcasts stated that he or she enjoys hearing the music broadcasts such as hymns. The music broadcast consists of instrumental music with religious themes. Despite both sermons, Quran reciting and music is based on religious themes; due to the context of the sound, one is preferred by everybody, while others are objected by some.

The participants were also asked about their satisfaction with the acoustics of the mosque and their satisfaction with the overall sound environment within the mosque. All respondents were satisfied with the acoustics but not all of them were satisfied with the overall sound environment. Sounds generated by people, such as coughing, talking, and sniffing, are perceived negatively by the respondents as their context is irrelevant and disturbing when you are inside the mosque. One respondent explained this as

It is not the acoustics of the mosque that is bad but the behaviour of the people. People do not act according to common decency, they produce all sorts of inappropriate sounds before, after and during the prayer which is very disturbing, annoying and makes you lose concentration.

\section{Place identity}

The spatial elements and activities which individuals use to define the identity of the space constitute the place identity category. Most common descriptors individuals used to describe the space are mystique, spiritual, tranquil, peaceful and impressive. Place identity is a direct response to interpretation of the soundscape. Many respondents said that music and prayer broadcast contributes to the mystique and spiritual atmosphere of the space: 
The Turkish folk music and Islamic music broadcast is very nice, I like to hear it and I think soft tune of Islamic music contributes to the mystique atmosphere.

The sole reason why I come to this mosque its tranquillity and I think the sound has a considerable impact on this. It should allure and attach me to the place.

Tranquillity of the space is a very commonly mentioned element and also an expectation from a religious space, which is greatly affected by the interpretation of the auditory environment.

\section{Outcomes}

The final category of the framework is the outcomes individual gives after being subject to the spatial and auditory characteristics of the mosque. During coding, most obvious outcome of the soundscape perception was found to be preferring to go to the mosque or not. Based on the spatial function, individuals have a general idea about this, which predetermines their sound preference and expectation from the soundscape. If the individual prioritises the religious function, he/she will prefer and expect to hear sounds that will fit into a context. Hymns or instrumental Turkish folk music are commonly appreciated in a mosque because they enhance the place identity and as they fit in the context they are interpreted positively. Even though the individual expects the space to be quiet, he/she can also approve this type of music broadcast, as long as it fits the context and has an appropriate sound level. Whether the soundscape keeps up the individuals' expectations and preferences influences how soundscape is interpreted and the place identity. If there is a sudden increase in the traffic noise, individuals' expectation will become obsolete. He/she will interpret the auditory environment negatively, as he/she expects and prefers religious spaces to be quiet; thus, the space will not provide the tranquil auditory environment our subject prefers. In the end, subject can respond to this sound environment by leaving the place. If same situation continuous over individuals next visits, his or her frequency of visit may reduce, thus his or her preference of the mosque.

\section{Discussion}

Brown et al. ${ }^{38}$ stated that in order to explore the perceived sound environment, the sound sources that contribute to the soundscape need to be identified. With regard to this, we have asked participants what they hear at that moment. However, it was interesting that vast majority of the respondents failed to list even the most obvious sound sources. A possible explanation could be low amount of sound awareness, and sound environment is not among the most important aspect of the space for this sample group. Respondents' common answer to this question usually consists of their soundscape expectation and soundscape preference in accordance with the religious function of the area. Respondents' answers, such as 'religious places should be quiet', indicate strong patterns between spatial function, soundscape expectation and interpretation of soundscape. The fact that even the ones who prefer to have a quiet sound environment in the mosque find music acceptable clearly shows the importance of context in soundscape. With regard to this, the findings are consistent with the ISO 12913-1.

The framework generated by this research has differences in terms of its components when compared to other GT and ISO 12913-1. On a closer look, it can be seen that even though the names are different, some items are actually closely associated. Even though 'Context' is not directly integrated to this framework, it has a major influence on item of this framework. Spatial 
function, soundscape expectation, sound preference, interpretation of soundscape and place identity all depend on the context of sound.

According to the literature, place identity is 'the symbolic importance of place as a repository for emotions and relationships that give meaning and purpose to life, reflects a sense of belonging and important to a person's well-being' ${ }^{39}$ In urban environments, designers/planners are using appearance and imageability of physical elements to form place meanings and satisfaction. 40,41 Findings indicate that interpretation of the soundscape helps forming the place identity, similar to how physical elements can form the place identity of an urban environment. One of the fundamental aspects of the soundscape concept is the meanings associated with the sound. ${ }^{42}$ Our findings are consistent with the literature that meanings associated with the sound influence the soundscape which contributes to the place identity.

When we compare the findings with the other qualitative research, we can see some differences. Both the researches conducted by Mackrill et al. ${ }^{29}$ and Acun and Yilmazer ${ }^{20}$ show that individuals can develop coping methods towards soundscapes. These coping methods are accepting, habituating/adapting, isolating from the sound environment and relocating to a different space. In this research, however, participants did not state anything about coping with the sound environment. Respondents stated discomfort caused by the street merchants, shops, traffic and disturbances caused by human activity in mosque. Even though it was not stated, it is researchers' remark that individuals are accepting and adapting to the sound environment of the mosque even if they get distracted, uncomfortable or dissatisfied. Individuals always have the option to go to another mosque, except during the prayer hours. Due to the nature of the Islamic worship activity, once the prayer session starts, individuals cannot leave the mosque until it is over. This leaves them with the only option of accepting and habituating to the soundscape. However, if there is a source of major discomfort or distraction, individuals can choose to go to another mosque for the next time.

The qualitative surveys conducted in indoor spaces consist of three types of spaces: hospital wards, open offices and now a mosque. The reason we do not see all of the aforementioned coping methods being adopted in all three types of these spaces is related with its function. When an individual get dissatisfied with the sound environment in a mosque, there is not anything much he can do besides accepting and habituating. In an office, however, there are varieties of possibilities. Accepting and habituating to the environment is an option here too, but an employee can also isolate himself from the sound environment through earphones or move to a more satisfactory location if able to. Based on this, it can be said that indoor soundscapes differ. Unlike urban, indoor soundscapes such as hospital, open office, mosque or a shopping mall need to satisfy different functions. A music that is played in a shopping mall might not be suitable for the context of an office or a hospital, and it can be completely inappropriate for a religious space, but shoppers can actually prefer it.

\section{Conclusion}

This article aims to analyse the sound environment of a historic religious space through a userfocused approach. GT is chosen as the main research method to collect and analyse the qualitative data. Analysis revealed six main categories that explain the association between the soundscaperelated elements (interpretation, expectation and preference), place identity and the spatial function. During the research, we have observed that the sample group has a relatively low sound awareness. This can be partially explained by the function of the building. Dominance of religious function of the space can possibly be causing all other aspects to remain in the background. Hence, visitors of the mosque do not prioritise the auditory environment. This points out to the fact that spatial function of the space places some boundaries in terms of soundscape expectation and 
soundscape preference, which affects the interpretation of the soundscape. However, it is seen that these soundscape-related elements have a notable contribution to the place identity even though the sample group has a low amount of sound awareness. The importance of the context is once again acknowledged by this research. Even though context is a category found in the created framework, it has a major influence on the interpretation, response and outcomes of the soundscape. Context is formed by the spatial function of the space. Then, context determines individuals' sound preference and soundscape expectation. Based on these two categories, individuals interpret the soundscape which enhances the place identity.

\section{Declaration of conflicting interests}

The author(s) declared no potential conflicts of interest with respect to the research, authorship and/or publication of this article.

\section{Funding}

The author(s) received no financial support for the research, authorship and/or publication of this article.

\section{ORCID iD}

Volkan Acun (iD https://orcid.org/0000-0001-9819-0233

\section{References}

1. Stump RW. The geography of religion: faith, place, and space. Lanham, MD: Rowman \& Littlefield, 2008.

2. Brace C, Bailey AR and Harvey DC. Religion, place and space: a framework for investigating historical geographies of religious identities and communities. Prog Hum Geog 2006; 30(1): 28-43.

3. Kayali M. Use of cavity resonators in Anatolia since Vitruvius. Int Inst Acoust Vib 2000; 3: 1621-1628.

4. Gül ZS, Çalışkan M and Tavukçuoğlu A. On the acoustics of Süleymaniye Mosque: from past to present. Megaron 2014; 9(3): 201-216.

5. Kayali M. Anadolu' da geleneksel akustik sistemler ve Mimar Sinan uygulamaları [Anatolian traditional acoustic works and works done by Sinan the Architect]. In: Proceedings of the 6th national acoustical congress, Antalya, 26-28 October 2002, pp. 233-228. Antalya: Turkish Acoustical Society.

6. Zühre S and Yilmazer S. The acoustical characteristics of the Kocatepe mosque in Ankara, Turkey. Archit Sci Rev 2007; 51(1): 21-30.

7. Ergin N. The soundscape of sixteenth-century Istanbul Mosques: architecture and Qur'an recital. J Soc Archit Hist 2008; 67(2): 204-221.

8. Suárez R, Sendra JJ, Navarro J, et al. The sound of the cathedral-mosque of Córdoba. J Cult Herit 2005; 6: $307-312$.

9. Gül ZS and Çalışkan M. Impact of design decisions on acoustical comfort parameters: case study of Dogramacizade Ali Pasa Mosque. Appl Acoust 2013; 74(6): 834-844.

10. Ismail MR. A parametric investigation of the acoustical performance of contemporary mosques. Front Archit Res 2013; 2(1): 30-41.

11. Truax B. Acoustic communication (communication and information science). New York: Ablex Publishing, 1984.

12. ISO 12913-1:2014. Acoustics - soundscape - part 1: definition and conceptual framework, 2014.

13. Brambilla G, Gallo V, Asdrubali F, et al. The perceived quality of soundscape in three urban parks in Rome. J Acoust Soc Am 2013; 134(1): 832-839.

14. Liu J, Kang J, Behm H, et al. Effects of landscape on soundscape perception: soundwalks in city parks. Landscape Urban Plan 2014; 123: 30-40.

15. Aletta F, Kang J and Axelsson Ö. Soundscape descriptors and a conceptual framework for developing predictive soundscape models. Landscape Urban Plan 2016; 149: 65-74. 
16. Davies WJ, Adams MD, Bruce NS, et al. Perception of soundscapes: an interdisciplinary approach. Appl Acoust 2013; 74(2): 224-231.

17. Bahalı S and Tamer-Bayazıt N. Soundscape research on the Gezi Park - tunel square route. Appl Acoust 2017; 116: 260-270.

18. Jeon JY and Hong JY. Classification of urban park soundscapes through perceptions of the acoustical environments. Landscape Urban Plan 2015; 141: 100-111.

19. Jeon JY, Hong JY and Lee PJ. Soundwalk approach to identify urban soundscapes individually. J Acoust Soc Am 2013; 134(1): 803-812.

20. Acun V and Yilmazer S. A grounded theory approach to investigate the perceived soundscape of openplan offices. Appl Acoust 2018; 131: 28-37.

21. Torija AJ, Ruiz DP and Ramos-Ridao AF. Application of a methodology for categorizing and differentiating urban soundscapes using acoustical descriptors and semantic-differential attributes. $J$ Acoust Soc Am 2013; 134(1): 791-802.

22. Kang $J$ and Zhang M. Semantic differential analysis of the soundscape in urban open public spaces. Build Environ 2010; 45(1): 150-157.

23. Glaser B, Strauss A and Strutzel E. The discovery of grounded theory: strategies for qualitative research. Nurs Res 1968; 73: 773.

24. Corbin JM and Strauss A. Grounded theory research: procedures, canons, and evaluative criteria. Qual Sociol 1990; 13(1): 3-21.

25. Jones $\mathrm{M}$ and Alony I. Guiding the use of grounded theory in doctoral studies - an example from the Australian film industry. Int J Doc Stud 2011; 6: 95-114.

26. Fiebig A, Schulte-Fortkamp B, Akustik T, et al. The importance of the grounded theory with respect to soundscape evaluation, 2004, pp. 349-350, http://www.conforg.fr/cfadaga2004/master_cd/cd1/articles/000246.pdf

27. Schulte-Fortkamp B and Fiebig A. Soundscape analysis in a residential area: an evaluation of noise and people's mind. Acta Acust United Ac 2006; 92: 875-880.

28. Liu F and Kang J. A grounded theory approach to the subjective understanding of urban soundscape in Sheffield. Cities 2016; 50: 28-39.

29. Mackrill J, Cain R and Jennings P. Experiencing the hospital ward soundscape: towards a model. $J$ Environ Psychol 2013; 36: 1-8.

30. Çankaya S and Yilmazer S. The effect of soundscape on the students' perception in the high school environment. In: Proceedings of the 2016 inter-noise, Hamburg, 24 July 2017, pp. 4809-4816, http:// pub.dega-akustik.de/IN2016/data/articles/000021.pdf

31. Hoda R, Noble J and Marshall S. Grounded theory for Geeks. 2011, pp. 1-17, https://hillside.net/ plop/2011/papers/E-13-Hoda.pdf

32. Glaser B and Strauss A. The discovery of grounded theory: strategies for qualitative research. New York: Routledge, 2009.

33. Strauss A and Corbin J. Basics of qualitative research: techniques and procedures for developing grounded theory. New York: SAGE, 1998.

34. Tanman B. Hacı Bayram-1 Verli Külliyesi. In: Islâm Ansiklopedisi. Ankara: Türk Diyanet Vakfı, 1996, pp. 448-454.

35. Eskici B. On the restorations of Ankara Haci Bayram Mosque. Turkish Stud 2014; 9(10): 557-576.

36. Acun V, Yilmazer S and Taherzadeh P. Perceived auditory environment in historic spaces of Anatolian culture: a case study on Haci Bayram Mosque. In: Proceedings of the 23rd international congress on sound \& vibration (ICSV23), Athens, 10-14 July 2016, pp. 1-8, https://www.iiav.org/archives_icsv_ last/2016_icsv23/content/papers/papers/full_paper_607_20160514131003763.pdf

37. Jeon JY, Hwang IH and Hong JY. Soundscape evaluation in a Catholic cathedral and Buddhist temple precincts through social surveys and soundwalks. J Acoust Soc Am 2014; 135(4): 1863-1874.

38. Brown AL, Kang J and Gjestland T. Towards standardization in soundscape preference assessment. Appl Acoust 2011; 72(6): 387-392.

39. Proshansky HM, Fabian AK and Kaminoff R. Place-identity: physical world socialization of the self. $J$ Environ Psychol 1983; 3(1): 57-83. 
40. Bruce NS and Davies WJ. The effects of expectation on the perception of soundscapes. Appl Acoust 2014; 85: 1-11.

41. Aksel E. City versus suburb: the effects of neighborhood location on place attachment and residential satisfaction. Ankara: Bilkent University, 2017.

42. Kang J, Aletta F, Gjestland TT, et al. Ten questions on the soundscapes of the built environment. Build Environ 2016; 108: 284-294. 